\title{
The Development Status and Prospects of Internet Finance
}

\author{
Xuan Guo ${ }^{1}$ \\ ${ }^{1}$ Nanjing University of Science and Technology ZiJin College, Nan Jing, China
}

Keywords: The Internet technology; Financial industry regulation; Supervision system; Arbitrage; Financing

\begin{abstract}
With the development of information and communication technology and Internet, the impact of Internet financial information on the financial markets has more and more restrictions to ignore. the Internet is common in people's life, which brought great changes to the financial industry, since the 2012 financial enters a period of rapid development of Internet, many enterprises in the development of the Internet financial, a lot of electricity in the Internet, in the tide of financial, known as the Internet is the financial industry has given rise to online third-party payment, P2P network, such as credit platform, online shopping, the suggests mode, these familiar business model no small impact to the traditional financial pattern. With the development of economy, the improvement of residents' income level, increasing the scale of residents' savings, how best to increase profits, also promoted the development of the Internet financial is the current problem that not allow to ignore. At the same time, the rapid development of Internet economy, Internet financial problems exposed one after another, better to solve these problems to promote the development of emerging Internet financial steady.
\end{abstract}

\section{The Characteristics and Development Environment of Internet finance Industry.}

\section{The Characteristics of Internet finance Compared with Traditional Model.}

In the traditional financial field, its business model is divided into business and management. Therefore, the traditional financial industry can easily cause the monopoly of the industry. For example, due to the strict and unified management of financial institutions by the government, non-financial institutions, especially those without governmental approval, are not allowed to engage in financial services, thus limiting many financial development opportunities and possibilities. After the approval of the government department, it is already quite high threshold. In addition, the product innovation of traditional financial model is not enough to attract people to buy and invest. Moreover, the traditional business model is cumbersome and inefficient, which makes customers complain. It is also the reason why the traditional financial industry has been slow and stagnated.

This new model is the combination of finance and modern communication technology, which is the form of the continuous evolution of the traditional financial industry. Throughout the Internet financial model, it has the following characteristics:

\section{Low Cost and High Efficiency.}

After the convergence of the Internet, the financial industry developed and shortened the complicated procedures of financial institutions, simplifying the various steps. Let the process of the financial industry be simplified and embodied in network payment and wealth management products. The time saved allows people to do more things. The fast network platform can save the necessary payment and reduce the cost of financial circulation. Therefore, they are loved by people.

\section{High Degree of Innovation}

On the Internet, you have what demand can be solve, whether you are shopping or eating, whether you are investment or business, the Internet will provide you with all aspects of the channel. For example, if you want to eat ,MeiTuan, Are you hungry; if you Want to go shopping , Taobao,JingDong will satisfy you; if you want to invest, all kinds of network wealth management product let you choose. It is not unreasonable that all kinds of products are popular with people.

Various Factors in the Rapid Development of Internet Finance.

Personal Assets Management Requirements 
Information technology is progressing and society is moving forward. The public's standard of living and consumption also changed. According to a recent survey, at least one of our people's lives is tied to the Internet, and phone users are everywhere. Therefore, this also provides great convenience for the network economy. With the improvement of people's income level, more and more people have the concept of financial management, and people are gradually no longer satisfied with the traditional financial services. Therefore, the emergence of the Internet also provides a convenient and concise channel for personal finance, and the benefits are much higher than the former. Due to its unique operation mode, it is not limited by time and space, low cost and high efficiency, which is well received by the majority of social groups.

\section{Advanced Technology and Data Service for Support}

The development of Internet finance complies with the needs of The Times. Through the operation of e-commerce platform, transaction information and other records are true and accurate to reflect the customer demand, and both parties can solve the supply and demand relationship through the platform. Of course, all of this information is symmetric. As an emerging economic model, the mode of operation is relatively flexible. Direct online transactions make people able to solve their needs even if they don't get out of the house. Its market speed is particularly fast, and what is required by that custom, what the platform provides, and accurate services is a great advantage. Internet finance can effectively save that management cost of retail, and can also get a certain size through the platform of the Internet for small financing, which is significant.

\section{Strong Support From Government Policies}

In policy, the state supports the development of Internet economy. In 2011, the people's bank of China began to issue third-party payment licenses. Since then, third-party payment has become a standardized payment method, breaking the monopoly of traditional economy. The executive meeting of the state council also held a meeting on Internet finance, proposing to regulate financial market, encourage microfinance and encourage the development of Internet finance industry. As the trend of the Internet age, its influence in the financial world has reached an unprecedented height. It's not just the policy of the state that has made a more specific demand for the development of Internet finance, but there's also a lot of supporting policies in the region, and it's not just in some of the more developed areas, but in some of the less developed regions of the country, and the country's various preferential policies have been supported.

Internet Financial Risk Factors and Management Measures.

\section{Internet Financial Risks.}

Internet finance has attracted a lot of attention at home and abroad, but it has a lot of risks in addition to enriching the content of our financial model. At the national level, China's Internet finance model is prone to defects. At present, China's financial system is still dominated by the system of planned economy, lacking the breath of commercial Banks and guiding the financial market through the government. In the financial system, there is no sound regulation and restraint mechanism in the country. The quality of the whole financial sector is weak, the overall service ability is relatively weak, the lack of service concept and risk awareness... At present, although the risks of Internet finance have been clearly recognized, some measures have been taken, but the Internet finance in the stage of rapid development still faces great risks. The reason is directly related to the risk supervision policy and the imperfect supervision. In conclusion, Internet finance is a new type of financial model, and its main various modes exist certain risks and imperfections, and its main manifestations are as follows:

\section{Performance of Information Security Risks.}

On Internet financial platform for business is a high risk, the risk from the level of Internet technology, the risk is mainly refers to hacking, phishing site, Trojan virus, fraud, etc. At present, network hackers have developed into an industrial chain, and hackers can use some network loopholes and professional tools to illegally invade other people's computer systems, thus 
completing the acquisition of confidential information.

The hacking tools can be used to achieve better attacks, to help hackers install hidden black chains on specific websites, and to trick users into clicking on links. Users are slightly distracted, and there is a high risk of theft of their account funds. Although Internet finance is popular, it does not mean that its users have high network technology, and if they are defrauded, they are likely to lose their money.

\section{Performance of Operational risk.}

Internet finance needs to take operational risks. In view of that present, the mobile payment of mobile phone does not require the use of a u-shield interface, and the use of Internet bank and a third party payment platform only require one handset authentication code to pay. This kind of payment method is extremely uncertain. When the mobile phone is lost, it is easy for the individual to let his information leak, and the key information will be leaked, which will bring economic loss to himself and his family. In the same way, when the rules of the Internet finance business are unfamiliar, the user could have an interruption problem at the time of payment, so that the same transaction would be done multiple times, and it would cost the consumer a lot of money. Sometimes, when we go to the store, the Internet cafes and public places to connect to the public wi-fi, it gives the hacker a chance to take advantage of the public's network, to steal the user's funds, and to take the risks that the user has to do.

\section{Performance of Credit Risk.}

Internet finance needs to bear all kinds of credit risks. The transaction is carried out on the network, the authenticity of the identity of the trading parties is difficult to be confirmed, resulting in serious asymmetry of information. In this case, once a scam occurs, it will damage the interests of the investors. Taking the crowdfunding investment model as an example, investors can transfer funds to investment projects through the registration of accounts on crowdfunding platforms. However, investors' funds are completely managed by crowdfunding platforms, and investors can't control them. Once the platform has problems, investors will face risks. In addition, the financial demand side of the Internet is usually unable to provide the collateral, so that investors need to bear a large credit risk. Because the Internet has a large virtual nature, investors can't really know the repayment ability and willingness of the fund demander. At present, there is a lack of a perfect personal credit evaluation system in China, so the demanders are easy to fake credit rating, and easy to obtain loans from multiple platforms. In cases where the number of defaults has exceeded the platform's tolerable limits, the platform's funds will not flow well, which in turn leads to the failure of the Internet banking industry.

\section{Performance of Business Risks.}

The Internet finance business needs to bear all kinds of business risks. When the liquidity of the Internet platform is in short supply, the balance of assets and liabilities will not correspond to the client's capital structure. Unlike traditional financial products, Internet financial products cannot be redeemed or redeemed more timely, which can cause losses to investors. Online funds do not guarantee true profitability, leading to business risk.

\section{Performance of Legal Risks.}

Internet finance is a legal risk. At present, China's laws and regulations on Internet finance are not very complete, and there are many places that cannot be touched. In other words, it is the loopholes in regulation that provide the opportunity for some profiteering criminals. With the fierce competition of the market, some platforms have provided a variety of financial security measures to attract customers. But, in fact, these financial security measures are not legal, and it's still a matter of concern. Once the platform is in trouble, a series of economic disputes can arise in the online transaction, leading to more legal liability to be investigated. The Internet financial service providers, for their own personal gain, in the absence of a legal operating permit, these operators began to engage in the Internet finance activities, but without the ability to take risks, they were able to evade the regulation of existing laws. From the perspective of monetary policy, the development of Internet finance has led to the development of virtual currency, which disturbs the relatively stable economic order. In terms of regulations, people can only use legal money to 
purchase virtual currencies, but there are still two kinds of two-way circulation phenomena, which will bring great difficulties to the work of financial institutions. And cyber criminals can use virtual currency for gambling and money laundering, which is why the currency has a big problem with security.

\section{Measures and Suggestions for Problems.}

The Internet not only from the enterprise internal financial risk, but also contains from the external legal risk, technology risk, risk. To effectively guard against financial risks, in addition to the construction of risk prevention mechanism, but also from the government, industry, enterprise and technology for risk prevention measures for the establishment of four Angle, thus better complete risk prevention.

\section{From the Government's Perspective:}

First of all, we need to improve the regulation of Internet financial products. On the consumer side, China already has a consumer protection law, but it is only aimed at ordinary financial products and services. There are few Internet oriented aspects, and the Internet financial industry is a high-risk industry, so the law enforcement is not enough. Of course, foreign countries have begun to pay attention and implement various legal measures, which undoubtedly has a good demonstration effect on China's Internet market. Secondly, we should establish a risk supervision and management system. The government supervision department should establish the risk supervision and management system according to the characteristics of Internet finance. In particular, the relevant departments should carry out both kinds of risks according to the existing data, analyze the advantages and disadvantages and strengthen the communication and collaboration between the inside. Third, establish a credit management system. In order to strengthen the prevention of Internet financial risks, the government should formulate corresponding legal system and regulatory standards to measure the standard of the whole industry. With the supervision of the government, a number of violainers could not find a loophole to drill and could help maintain the whole of the circle.

\section{From the Perspective of the Whole Industry.}

Establishing a joint risk prevention mechanism. With the development and growth of Internet finance, the level of investor and participant is ragged, so as to prevent the risk of credit risk in various operations and to reduce the asymmetrical information of user information, it should establish a risk monitoring mechanism in the industry to realize the discipline of Internet finance industry. In terms of financial disclosure, Internet enterprises should try their best to be open and transparent, and provide transparent and transparent data to users to meet their investment needs after removing the business secrets. Secondly, the Internet finance industry should also realize the reasonable cutting of operation correlation, so as to ensure the smooth construction of the industry firewall mechanism.

\section{From an Enterprise Perspective:}

Strengthen the application of electronic signature technology. In order to prevent the information from being stolen, we should strengthen the signature technology of the enterprise. In the process of electronic transactions, we should try to take the offline face to face to prevent the security of the property. Strengthen the use of big data. Cloud computing, the development of big data makes it possible to use Internet technology to achieve a large number of continuous data of individuals or enterprises, which reflects the behavior status of individuals or enterprises. The comprehensive analysis of these data using big data technology can realize the effective identification of individual or enterprise identity. Therefore, Internet financial enterprises can reduce the risk of user identification by strengthening big data and provide security for users' information security.

\section{From the Perspective of Investors.}

Before carrying out the investment of the financial products, it is required to take into consideration the actual situation, take into account the risk nature of the own property and its own repayment ability, and make a "measure best effort", not blindly pursue the huge interest, and measure the countermeasure against fraudulent activity such as credit, the investor will strengthen the risk prevention consciousness, increase the ability of the risk of identification, understand the 
information of the platform before the investment, and judge the information of the platform before the investment. The selection of the financial platform is not blind, and the physical nature of the phenomenon, the field visit and the high vigilance during the investment process can be observed. If necessary, also find out if some of the network lending platforms have a cooperative guarantee company. The choice of the financial platform. The investor selects a standardised web credit platform investment. Contrary to the spurious network lending platform, the specification 's platform is not only in the public disclosure of the detailed information, but is fully aware of its operational status. When choosing a platform, investors should give priority to the choice of local platforms so as to facilitate the field investigation and better understand the information of the platform. When investing, investors should also diversify their investments, namely, bidding on multiple standard platforms, thus effectively avoiding investment risks.

\section{Reference}

[1] Ma chuang. A brief discussion on the future of commercial Banks from the rise of Internet finance [J]. Economy, 2014(11):117-118.

[2] Lu min feng, Yang liang. The development status and growth prospects of green Internet finance -- based on a review of the connotation of "green finance" [J]. Rural finance research, 2017(7):37-42.

[3] Zhang yuansheng, Yang jian, zhang peng. Discussion on the development status and prospect of Internet finance [J]. Abstract: economic management, 2015(7):226-226.

[4] Cao guohua, zhang bingqi. The current situation and prospect of Internet finance [J]. Business economics research, 2014(6):78-80. 